\title{
Particularidades da tutela jurisdicional do direito à saúde
}

\author{
André R. C. Fontes ${ }^{1}$
}

\begin{abstract}
Resumo
O artigo é uma crítica à disciplina das liminaresda Justiça para a internação hospitalar e dos efeitos dessas decisões no sistema brasileiro de saúde.
\end{abstract}

Palavras-chave: Internação; Decisão; Liminar.

\begin{abstract}
The article is a criticism of the discipline of theinjunctions of Justice for hospitalization and the effects ofthese decisions on the Brazilian health system.
\end{abstract}

Keywords: 1 Hospitalization; 2 Decision; 3 Injunction

Toda sociedade é composta por pessoas; e poderia ser lógico começar um estudo de Teoria Geral do Estado ou mesmo de Direito Constitucional pelas características daqueles indivíduos como um tema central e destacado de tratamento e estudos do Direito. E o exame de temas conexos obrigaria cada sistema jurídico a afirmar as situações nas quais estão assentadas a existência humana e o bem-estar de todos e a proscrever todocomportamento que ponha em risco o corpo vivo de uma nação. Por isso, a concepção mais elementar da condição humana - a saúde de um povo -, haveria de ser o mais fundamental dos direitos tutelados pelo Estado moderno. É, pois, necessário desde logo salientar que, uma dada sociedade não é um simples conjunto de indivíduos, senão um sistema complexo e dinâmico no qual os homens nascem, vivem e morrem - mas que a sociedade por eles integrada, vista como um grande e vigoroso sistema, tem que perdurar.

Qual seria, pois, o caráter desse sistema de saúde de todo um povo? Que traços distintivoshaveria de se tomar por base para se destacar seus elementos a fim de abranger toda a população? Na experiência brasileira conhecemos formações variadas de tempo e lugar

\footnotetext{
${ }^{1}$ Doutor em Direito pela Universidade do Estado do Rio de Janeiro (UERJ), Professor na Universidade Federal do Estado do Rio de Janeiro (Uni-Rio) e Desembargador no Tribunal Regional Federal da 2a Região (Rio de Janeiro e Espírito Santo).
} 
na qual a vida social conduziu a um conjunto estruturado de direitos e deveres relacionados ao indivíduo e ao Estado cobertos por leis para o seu funcionamento e desenvolvimento.

Não é difícil compreender a existência, assim, de um Direito à Saúde. Essa veracidade assegura que possamos dar início a uma análise científica e objetiva das noções e conceitos que o envolvem. Deixando de lado a divisão dicotômica do Direito, no qual Público e Privado cercam de todos os lados a vida humana, lembramos que, no âmbito privado, as normas sobre saúde são de ordem pública e são igualmente revestidas de umindiscutível interesse social. Compreende também os pressupostos de inteligência e vontade, isto é, o entendimento do que representa cada ato de proteção à saúde e a manifestação do que o beneficiado quer e necessita. Assim é que, se uma pessoa sofrer momentânea ou transitoriamente a perda de sua consciência, não faz com que seus direitos sejam incertos ou discutíveis, mas, ao contrário, que seus direitos sejam - como é de se esperar! - instrumentalmente alcançados com o aparato médico posto à disposiçãode todos.

A enorme importância dada à tutela geral da saúde traduz-se no fato da sua própria conquista, geralmente associada a um novo tipo de Estado, que deixa suas vestes liberaise se assume como um Estado Social de Direito. Uma discussão acadêmica sobre a afirmação do Estado Social para a existência e concretude de um direito à saúde seria neste momento mais acadêmica que positiva, e ofereceria pouco interesse neste texto. Portanto, essa associação é nestas linhas uma mera digressão, sem que se queira tomar como tema principal ou mesmo provocar mais outras reflexões do mesmo naipe.

Para encontrarmos no direito da saúde o objeto necessário aos estudos, por outro lado, não basta identificarmos seus aspectos mais externos. A exteriorização da norma jurídicaé condição mesma da sua existência, mas, não deve significar uma redução do direito à saúde à uma concepção monolítica de direito, na qual reflete somente o juízo normativo extraído de um texto legal ou constitucional. É preciso refletir sobre seu aspecto interior e considerar que é um direito social e simultaneamente um direito individual. Inclui-se nesse raciocínio um desenvolvimento de grau de madureza que se medem, ante tudo, pelo nível de desenvolvimento entrelaçado ou cruzado com o grau de aperfeiçoamento desse direito social com o individual. E não se assemelha diretamente nem à necessidade nem ao objeto da necessidade como nenhum outro direito. É um instrumento que não pode serutilizado para satisfazer diretamente uma única necessidade. E analisado mais detalhadamente forma situações cruzadas de interesse social e individual simultaneamente que não encontram paralelo em todo os sistema jurídico do Brasil.

Cumpre assinalar que o aparecimento de uma concepção consistente e definida de um direito à saúde provocou variações na forma da sua interpretação e aplicação pelos mais diversos operadores. Essas variações tinham um cunho tanto de qualidade quanto de quantidade no que se poderia denominar de concretude dos direitos. A continuidade desse direito proporcionava um ambiente de desenvolvimento tão apurado ao ponto de absorvero 
maior número de situações aos membros da sociedade, mas invariavelmente manifestava-se de fato nas variações quantitativas que se verificavam pela intervenção doPoder Judiciário. Independentemente da velocidade que o tema era agasalhado pela magistratura, a quantidade de decisões determinou uma tal variação quantitativa que a natureza ou qualidade dos direitos foi igualmente afetada.

Ao se manifestarem a respeito do assunto, os juízes, já coberto por uma razoável políticalegislativa, fixaram limites que parecem alterar mesmo a essência da lei. Esclarecendo a essência mencionada, diremos que a interdependência do direito da saúde para uma decisão judicial condicionou o sistema do direito à saúde e o afetou negativamente em prejuízo do seu caráter necessário e universal. Aqui tem grande importância a distinção entre aqueles que em condições financeiras especiais e conhecimentos aprimorados de advogados buscaram decisões judiciais e acumularem vantagens próprias de um Poder que, mais aberto aos litigantes habituais e com melhores conhecidos de patrocínioadvocatício encontraram êxito em detrimento de uma massa de necessitados já postos à latere por um Poder que, com peculiares e especificidades pode afetar o exercício de umaatividade estatal ampla e universal por um órgão do Executivo. É importante chamar atenção para o significado conceitual da solução judiciária não ter como elemento de seuconceito o caráter uniforme e ecumênico.

O inegável salto de qualidade que o Judiciário imprimiu à tutela da saúde não proporcionou uma correspondente forma universal de mudança e de benefício para todos aqueles que careciam de proteção. Na compreensão desse salto de quantidade, é necessário especificar as condições concretas e uma virada decisiva na falta de tratamentoisonômico entre os usuários do sistema de saúde. Dois são os saltos: um de aumento da quantidade e outro da falta de universalidade paritária entre os destinatários. E é importante lembrar que compreensão desta análise ser o Judiciário, por natureza, casuístico nas soluções dos problemas universais de saúde no País.

Se a tutela jurisdicional é o centro dos princípios mais efetivos e conhecidos na temáticados direitos à saúde, é também a força motriz de uma das mais evidentes contradições deuma justiça paritária no Brasil. E as contradições não se caracterizam pela diversidade de opiniões entre os juízes, já que a diversidade de opiniões e razões de decidir são da própria formação do convencimento individualizado em todo julgamento em espécie, mas sim, pelas contradições externas resultantes da melhor capacidade e talento de um advogado em relação a outro na busca da atenção e da tutela jurisdicional a provocar, como uma lógica consequência o tratamento diferenciado, com uma mais acentuada efetividade ao melhor assistido por advogado e, portanto, atendido judicialmente, e não ao mais necessitado da tutela jurisdicional da saúde, que nem sempre é bem servido de assistênciajudiciária. Essa complexidade e contrariedade do movimento judicial em relação ao maiscarente de direito da saúde afasta deliberadamente uma posição que, $a b$ origine, haveria de ser a vocação necessária e universal do sistema de tutela à saúde.

$\mathrm{Na}$ apuração e na medida que cresce o problema, é mister evidenciar se a amplitude das decisões judiciais não demandariam uma tutela coletiva dos direitos de saúde. Ao se 
esclarecer o papel da tutela coletiva aos casos dos direitos de saúde, a solução judicial coletiva de dar ampla proteção a todos os necessitados poderia ser a opção de oferecer, não apenas ao litigante representado judicialmente, mas a todos aqueles quenecessitassem de um abono judicial. Elevada ao extremo, essa posição corresponderia ade um verdadeiro programa de ação pública coordenado pelo Poder Judiciário, e que, emúltima perspectiva, se confundiria com os objetivos de um programa de ação de uma autoridade pública e redundaria - pasmem! - em uma política pública setorizada, desprovida da legitimidade e do compromisso social para tal agir (por ausência dos elementos políticos que encerram o Poder Executivo e Legislativo.

Considerando que a verdadeira natureza dos direitos sociais é a sua universalização e múltipla difusão, a apuração de uma caráter individualista das decisões judiciais em sua essência e realidade, podem gerar a aparência e a ilusão de uma justiça efetiva para cadaum dos demandantes. É que se a tarefa da tutela da saúde é a sua ampla e universal aplicação, subtrair a dimensão coletiva de uma solução e criar variações de tratamento poderá significar um verdadeiro retrocesso na expansão democrática do papel do Estadoe uma degradação dos direitos sociais dura e custosamente conquistados.

Reconhecer o fato de um duplo sentido da solução judicial para os direitos, por não coincidirem no tratamento único dado à saúde aos vários titulares de direitos à saúde pode implicar na potencialização das soluções judiciais e um movimento em favor dos mais favorecidos economicamente, em detrimento das formas governamentais de aplicação de políticas públicas de saúde aos menos favorecidos.

A pendência de julgamentos em matéria de saúde faz com que as circunstâncias deem o signo da dificuldade até mesmo para uma reconstrução sistemática de uma tutela constitucional da saúde. A multiplicidade de controvérsias pode além de não dar soluções justas individualmente servir de fonte de abstenção de formulas legislativas, até mesmo que venha a facilitar as vias judiciais somente para o grupo mais haibilidoso.

Dos diversos argumentos acima expostos acrescentam-se e seguem ainda um dos mais caraterísticos do regime judiciário do Brasil: a dupla sistemática de órgãos judiciários da União (Justiça Federal) e dos Estados (as Justiças Locais). E quando as entranhas da formação judiciária brasileira se revelam, deixa de existir uma coesão dos órgãos jurisdicionais e brota uma verdadeira forma de concurso que alarga a dificuldade com a diversificada cultura de cada grupo de órgãos judiciários, que não raramente assumem uma função subsidiária ao outro sempre que a solução não foi encontrada por um, além da possiblidade de fraudes por repetições de demandas resultantes de litispendências não apuradas. O certo é que essas condições da estrutura do Judiciário não permitem uma forma integrada, de modo a conjugar os dois conjuntos de órgãos jurisdicionais em uma função supostamente mobilizadora ou transformadora do desenvolvimento e do progressoda tutela jurisdicional. E assim prevalece um tipo de liberdade de se provocar o Judiciárioque não permite que se expresse claramente uma harmoniosa atividade jurisdicional na qual vigorem nos dois diferentes órgãos os mesmos entendimentos. Ao vigorar em nossodireito esse sistema dividido e parcial, a eficácia do sistema de tutela jurisdicional de saúde estará a promover vantagens e privilégios aos mais capacitados perante a autoridadejudiciaria, por 
conta da competência de seus advogados, e em correspondência toda a restrição e injustiça aos demais.

Ao se compreender racionalmente a tarefa do Judiciário no Direito à Saúde devemos noslembra da tríplice divisão dos direitos fundamentais, a partir de uma dupla distinção positiva e negativa entre direitos e garantias: direitos de abstenção, nos quais se quer o Estado se abstenha, por exemplo, de criar obstáculos à nossa liberdade; os direitos de prestação, nas quais o Estado deve agir de modo a realizar uma prestação específica, comoseria exemplo uma prestação jurisdicional, além das garantias, que sempre visam a dar condições a que um direito (ou mesmo uma outra garantia) seja apreciado, como, verbi gratia, o devido processo legal.

Posto seja anunciado como um direito social - o que levaria ao raciocínio de um direito subjetivo público, categoria jurídica que não confrontaremos neste texto - oreconhecimento de um direito fundamental à saúde assim se generalizou na literatura jurídica e nos jugados dos tribunais do País. Essa compreensão aparentemente simplista no complexo tema dos direitos fundamentais tornou-se claramente a chave da intervençãojurisdicional no direito da saúde. Em torno dela o Judiciário brasileiro conferiu lucidez eprecisão no endereço que fixa os parâmetros para o reconhecimento pretensamente generalizado de direito de prestação jurisdicional em matéria de saúde.

Lembramos de forma sucinta que a Saúde é teoricamente anterior à própria questão mesmo da Medicina. Nas intermináveis extensões do País, podemos verificar um contraste nítido entre os padrões de morbidade e mortalidade nos diferentes estratos da população, que correspondem grosso modo à uma diferenciação análoga na prestação pública, estatal e institucionalizada de serviços de saúde. Essas contradições e equívocosna estrutura de saúde no Brasil mostram que a crise na saúde não se confunde com a criseda Medicina. Nesse ambiente de soluções individuais geniais dos magistrados, uma dicotomia entre Saúde e Medicina - sempre presente nas políticas públicas no País-, não encontra reconhecimento na intervenção judicial, que não consegue, na sua vocação de entregar a prestação jurisdicional restrita e individualizada, estabelecer a fronteira clara entre uma e outra.

Uma vez consolidado um julgamento específico, a distinção entre Saúde e Medicina nãosomente não ocorre, como essa correlação passa a ser fruto de um pronunciamento único, ou seja, um todo-único, no qual a natureza legal (ou constitucional) do direito elaboradona sentença pelo juiz torna impossível qualquer distinção sustentável entre o corte da Saúde e o que seria o corte da Medicina. E para evitar um possível mal-entendido, lembroque a evolução de uma doença é incompatível com a dinâmica Saúde-Medicina na Justiça,não somente pela desconsideração do decurso do tempo inicialmente em um processo, mas, também, porque o Judiciário não é apto a fazer mudanças técnicas no tratamento deuma pessoa a tempo de significar uma necessidade atual e imediata.

Sem pretender reproduzir completamente o ambiente judicial, a redução de todo um sistema de saúde pública a uma decisão judicial submete as exigências médicas ao risco das oscilações da jurisprudência e das soluções judiciais no curso de um processo agravado com 
o risco mesmo de uma cirurgia ou um tratamento de urgência não ser realizado devido aos efeitos de uma coisa julgada (ou sua ausência), entenda-se que nesse momento já seja desatualizada e inútil.

Não é em virtude do apego singular de resolver conflitos que o juiz é chamado para as questões de saúde, mas para realizar ou fazer realizar prestações de caráter assegurar e ade prestar assistência aos necessitados, pois assegura, dentre outras prestações assistenciais, também aquela farmacêutica.

Problemas de operações negociais e de execução de contratos entre os agentes econômicos que produzem e operam fármacos e seus correspondentes conduzem ao agravamento da questão pelas controvérsias relacionadas com os direitos de patentes. Sobre esses produtos (patentes), muito longe da ideia de imprescindibilidade de um tratamento ou de impossibilidade na substituição de produtos farmacêuticos por outro temlevado o Judiciário mais a tutelar a própria patente dos remédios que o sensível e impreterível direito de saúde, que é, de modo central, constitucionalmente tutelado comoum direito fundamental.

A imposição de tratamentos gratuitos por decisões judiciais, máxime com remédios específicos de determinados laboratórios, geralmente com a absoluta exclusão de qualquer outro por causa da direitos de propriedade intelectual, converte aparentessoluções por certos produtos em solução única. E um dos sustentáculos artificiais da procura de determinados medicamentos, geralmente envolvidos pela aura de solução única e quase milagrosa, em custos que destoam os padrões internacionais. Essa realidadede preços cobrados por remédios aproxima-se do abuso, especialmente por não ter nenhuma relação com a pesquisa ou desenvolvimento do produto. E não cabe a menor dúvida de que será conta em branco a ser satisfeita com o Orçamento Público.

São necessárias certas observações complementares no abono de decisões judiciais que fixem gastos a serem deduzidos do Orçamento Público. Conquanto não se considere mesmo a eficácia terapêutica do remédio, a despesa pública por ordem judicial estará longe de prestigiar a legitimidade dos valores e a homenagem ao compartilhamento socialdos gastos sociais em saúde. E no pórtico das vicissitudes judiciais de saúde, é comum mesmo que a determinação de entrega de produtos sem o comprovado reconhecimento terapêutico ou que tenha sequer suplantado a mera condição experimental - o que significa dizer que, mesmo sujeito aos licenciamentos de comprovação terapêutica não chegou mesmo a merecer ciência da Vigilância Sanitária.

A coisa julgada reverte-se de um tipo de pretensão de perenidade - já que não é limitadano tempo - que em referência aos remédios destinados ao tratamento das graves condiçõesou sintomas mórbidos e que exigem terapia de longa data que, muito longe estarão de serem compatíveis com uma situação de urgência. Não se pode sequer ignorar que uma situação de urgência de doenças de algo risco ou mesmo doenças crônicas para um tratamento ou uma cirurgia não estaria certamente contemplada em uma sentença resultante de um longo e penoso decurso de um processo, fique impedida de ocorrer por ausência de uma simples menção desse aspecto na redação do julgado levado a efeito.

A essência única e a variedade das formas de ratio cognoscendi de um profissional de 
Saúde ou Medicina sobre a natureza, extensão e mesmo proporcionalidade do direito à saúde a respeito de uma única vida, de tal modo poderia levar a dúvidas que nem mesmouma verdadeira prova não deixaria de ser confrontada nas diversas situações possíveis navida de um paciente, e pior: a justificar a ratio decidendi formadora de uma sentença porum juiz juridicamente convencido, mas tecnicamente equivocado questão da saúde..

Por essas questões, é inevitável que se tenha de devolver ao juiz uma série de controvérsias médicas que podem exigir uma solução de urgência ou de estar condicionada à uma estrutura médica de equipamentos específicos, sem os quais o paciente correria risco de vida que, a despeito de todo zelo e denodo judiciais, ficariam diluídas em um ambiente litigioso coberto por todo tipo de vícios, que podem estar longede ser corrigidos devido, por exemplo, a uma preclusão para o próprio juiz, a preclusão pro judicato.

A própria identificação de um conteúdo essencial do direito à saúde pode não corresponder àquela informada ao juiz tal como foi a ele submetida e que tenha merecido apreciação feita da questão. A prestação de diagnóstico e mesmo o custo que se teria na estrutura hospitalar, assim como a própria caracterização da doença, pode não ser aquelaque corresponderia à necessidade de integridade física do paciente.

Essa tensão entre a realidade e a necessidade do tratamento que se quer ver abonada e osjuízos sobre a lei ou mesmo sobre a jurisprudência a que estaria submetido o julgado podem estar longe de ter uma correspondência. E não é raro que ocorram decisões sobresituações de urgência que já não são mais úteis ou necessárias ou que não foramagasalhadas por alguma decisão judicial ou decisão oportunamente adequada e tempestiva. As transformações da realidade que o imediato atendimento em distintos locais e em momentos específicos venham a exigir, de modo que se persiga clara e verdadeiramente o direito amparado pelos direitos sociais constitucionalmente protegidosencontra-se limitada pela própria natureza do sistema de tutela de urgência por suas peculiaridades e particularidades.

As ulteriores anomalias representam substancialmente os desafios aos próprios limites dosistema judicial no que se poderia denominar de confronto com aquele regime de ofertas de serviço público que deveria ser prestado diretamente pelas instituições oficiais. E a evolução desse estado de coisas do direito à saúde leva à discussão sobre o grau ou limitesdo acerto judicial sobre a saúde em geral. A perspectiva consistente em um imaginário noqual o direito à saúde deduzido em juízo encontrasse no Judiciário a disponibilidade queassegurasse as formas adequadas de exigências de tutela do direito à saúde parece tornar-se impraticável sem as variantes e contornos exemplificados nas premissas aqui lançadas.

É necessários que nos detenhamos especificamente nas ideias iniciais que levam a uma temática no direito à saúde. A previsão constitucional está longe de ser alcançada pelos desafios a que o Judiciário está submetido. Essa solução por sentença para as controvérsias em matéria de serviços de saúde, submetida ao discrimine da jurisdição, mantido seu estado atual, vai exigir a reconstrução da doutrina que descreve os direitos sociais venha a cair nos limites da reserva do possível e sem ser operada pela forma unitária que a experiência judiciária consolidou. 
As medidas que se pretendem podem corresponder às variadas exigências de tutela daqueles cobertos pelo patrocínio do mais competente dos advogados. Mas o riscos de uma incapacidade última dos problemas de saúde, mais propriamente se aproximam de uma verdadeira metamorfose de desconstituição dos direitos sociais que uma evidência de uma possível e esperada convergência interinstitucional no específico setor de saúde.

\section{REFERÊNCIAS}

ALMOND, Gabriel A.; COLEMAN, James S. A política das áreas em desenvolvimento.Rio de Janeiro: Freitas Bastos, s/d.

BACRE, Aldo. Teoria general de processo. Buenos Aires, Abeledo-Perrot, 1988.

BUCCI, Maria Paula Dallari. Judicialização da saúde. São Paulo: Saraiva, 2017.

BUSNELLI, Francesco Donato. Tutela dela salute e diritto privato. Milano: Giuffrè,1978.

DEL RÍO, Andrés; MARTON, Silmara Lídia. Os desafios das politicas públicas noBrasil. Curitiba: CRV, 2016.

FARIA, Lina. Saúde e Política. Rio de Janeiro: Editora Fiocruz, 2007. FIGUEIREDO, Mariana Filchtiner. Direito à saúde. $2^{\mathrm{a}}$ ed. Salvador: Podium, 2011.

FISCHLOWITZ, Estanislau. Fundamentos da política social. Rio de Janeiro: Agir, 1964.

GALLO, Carlo Emanuele; PEZZINI, Barbara. Profili attuali del diritto alla salute.Milão: Giuffrè, 1998.

GUISE, Mônica Steffen. Comércio internacional, patentes e saúde pública. Curitiba:Juruá, 2007.

MARANHÃO, Clayton. Tutela jurisdicional do direito à saúde. São Paulo: RT, 2003.

MARQUES, Marília Bernardes. Saúde pública, ética e mercado no entreato de dois séculos. São Paulo: Brasiliense, 2005.

MELLO, Celso Antônio Bandeira de. Conteúdo jurídico do princípio da igualdade. $3^{\mathrm{a}} \mathrm{ed}$. São Paulo: Malheiros, 2003.

MELLO, Daniela Tranches de. Movimentos sociais e institucionalização de políticas públicas de saúde no Brasil. Rio de Janeiro: Mauad, 2015.

OSMAN, Roberto. Saúde mental: os direitos fundamentais. Rio de Janeiro: Artaud, 2008.

POSSAS, Cristina. Saúde e trabalho. Rio de Janeiro: Graal, 1981.

PRÉTOT, Xavier; DUPEYROUX, Jean-Jacques. Droit de la sécurité sociale. $9^{\mathrm{a}}$ Paris: Dalloz, 2000. 
SILVA, Júlio César Ballerini. Direito à sáude. Leme: Habermann, S/d.

SILVA, Paulo Roberto Coimbra; SOUSA, Simone Letícia Severo. Direitos e políticas públicas. Belo Horizonte: D’Plácido, 2015.

SOUSA, Simone Letícia Severo e. Direito à saúde e políticas públicas. Belo Horizonte:Del Rey, 2015.

TORNAGHI, Hélio. Comentários ao Código de Processo Civil. 2a ed. São Paulo: RT,1976.

TORRES, Manuel de. Teoria de la politica social. 2a. Madri: Aguilar, 1954. 